\title{
Change Point Detection and Trend Analysis of Rainfall and Temperature Series over the Vellar River Basin
}

\author{
Supriya Palaniswami*, Krishnaveni Muthiah \\ Centre for Water Resources, College of Engineering, Anna University, \\ Guindy, Chennai-600025, India.
}

Received: 31 May 2017

Accepted: 18 September 2017

\begin{abstract}
Rainfall and temperature have been extensively considered as an initial point toward the apprehension of climate change progressions, establishing one of the important constituents of the hydrological cycle. The purpose of the present study is to examine the variability of rainfall and temperature for better understanding of the hydrological environment of the river basin located in northern Tamil Nadu. Mann-Kendall and Sen's slope tests were employed for monthly, seasonal, and annual temperatures, and also for annual maximum daily rainfall, seasonal, and annual rainfall statistics. A change point detection test was applied for annual maximum and minimum, mean temperature, and annual precipitation series. The results revealed that all the monthly, seasonal, and annual maximum, minimum, and mean temperatures have a significant greater rising trend. The magnitude of increasing trends in NEM (northeast monsoon) and SWM (southwest monsoon) are greater than that of summer and winter seasons for almost all the rain gauge stations. The maximum temperature and minimum temperature change points are identified in the years 1985 and 2001 and 1987 and 2013, respectively. From the mean annual temperature, it is seen that the change point is present in 1983-88 and 2000-04 at 100\% confidence interval.
\end{abstract}

Keywords: trend, change point, climate change, hydrological environment, river basin

\section{Introduction}

The Fifth Assessment Report (AR5) released by the Intergovernmental Panel on Climate Change documented that the rise in global temperature since the last century is definite both over land and ocean and that the last three decades have been warmer compared to any other previous decades in instrumental records. Changes in precipitation

*e-mail: supriya@annauniv.edu in particular extreme events can intensely increase the vulnerable population and affect the adaptation capability under the predicted future climate change scenarios by the middle and at the end of the 21st century [1]. The work [2] reviewed numerous studies on trend analysis of rainfall, temperature, and rainy days all over India and perceived that the trend and its magnitude is assessed recurrently by Mann-Kendall and Sen's slope estimation tests. Furthermore, they documented that the river basin in the northern part of Tamil Nadu is experiencing an increase in rainfall and decrease in rainy days, which implies that more intense floods will occur. A significant 
change in discharge in the middle reach of the Yellow river analyzed by the non- parametric Mann-Kendall and Pettitt tests revealed that the methods act as a powerful tool for evaluating the previously implemented soil and water conservation measures [3]. A Mann-Kendall trend test is utilized to analyze evapotranspiration sensitivity to changes in meteorological variables, revealing that the method can be used as a water management tool with proper measures to evade climate change impacts [4]. A highly increasing annual temperature trend is identified with the long-term data 1901-2012 using Mann-Kendall test at $95 \%$ confidence level for Tbilisi, Georgia, and also reported that monthly temperature data provided insignificant trends [5].

A study [6] investigated trend and change point detection of annual and seasonal precipitation and maximum, minimum, and mean temperature for southwest Iran. The results revealed insignificant trends in precipitation and significant increasing trends in temperature using Mann-Kendall and Pettit's test. The change points are observed in temperature time series that began in the 1990s. The author [7] analyzed the time series of trend and change point detection for temperature, relative humidity, wind speed, sunshine hour, and pan evaporation using non-parametric tests. Their results showed that a significant change point was present during 1900-2000, and a significant rising trend observed in temperature and falling trend is reported for other climate variables. The agricultural and livestock sectors are affected not only by rainfall and temperature, but also by other climatic variables such as wind velocity and relative humidity [8].

A work [9] compared four different change point detection methods such as Bayesian analysis of change points (BCP), wild binary segmentation (WBS), E-agglomerative algorithm (E-Agglo.), and iterative robust detection (IR). Their results implied that BCP gives incorrect change points, and that E-Agglo and WBS provide correct location and the number of change points, but E-Agglo is computationally costlier and WBS takes less time for estimation. If a dataset has both trend and change point, analyzing with only one method can give erroneous results. A new approach is developed using locally weighted polynomial regression and segmented regression for trend and change point detection for water quality parameters. The method helps in environmental and pollution control decision making especially suited for irregular datasets [10]. Several studies have been carried out by researchers all over the world in trend analysis and change point detection [11-14].

The present work attempts to understand the variability of rainfall and temperature in order to improve the hydrological environment of the river basin. The study area is located in northern Tamil Nadu and covers an area of $7,520 \mathrm{~km}^{2}$. The boundaries of the basin are delineated by the Bay of Bengal in the eastern side, the Kalvarayan Hills in the western side, by Ponnaiyar Basin in the northern side, by Paravanar Basin on the northeastern side, and by Cauvery Basin on the southern side (Fig. 1).

\section{Material and Methods}

\section{Mann-Kendall Test for Trend Detection}

The Mann-Kendall test is a widely used non-parametric test utilized for trend detection in environmental sciences

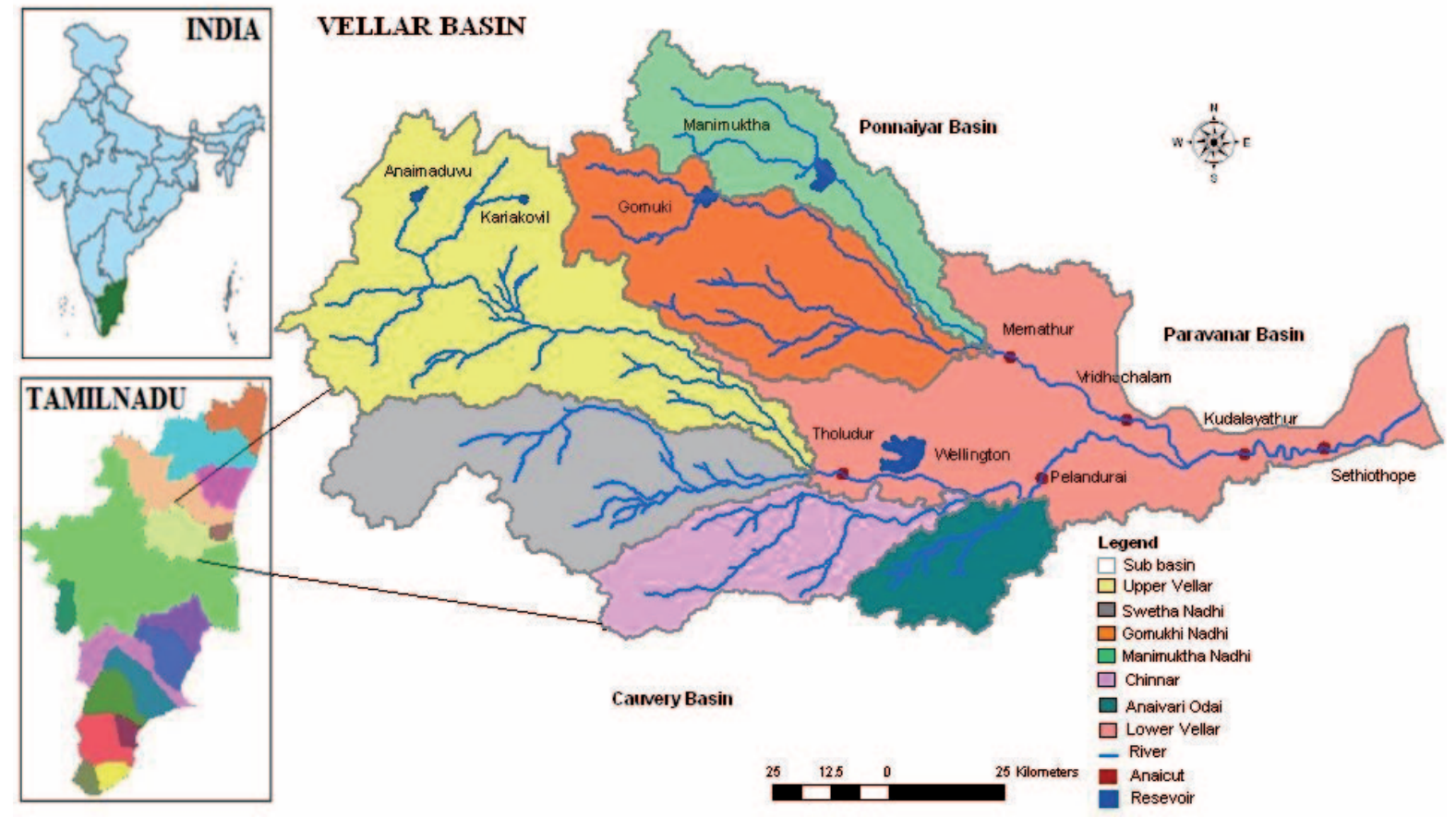

Fig. 1. Vellar River Basin of Tamil Nadu, India. 
[15-16]. The standardized test statistics Z and MannKendall statistic $\mathrm{S}$ is given by,

$$
\begin{gathered}
S=\sum_{i=1}^{n-1} \sum_{j=i+1}^{n} \operatorname{sgn}\left(x_{j}-x_{i}\right) \\
\operatorname{sgn}\left(x_{j}-x_{i}\right)=\left\{\begin{array}{c}
+1, \text { if } X_{j}-X_{i}>0 \\
0, \text { if } X_{j}-X_{i}=0 \\
-1, \text { if } X_{j}-X_{i}<0
\end{array}\right.
\end{gathered}
$$

$\operatorname{Var}(S)=\frac{1}{18}\left[n(n-1)(2 n+5)-\sum_{p=1}^{q} t_{p}\left(t_{p}-1\right)\left(2 t_{p}+5\right)\right]$

$$
Z=\left\{\begin{array}{l}
\frac{S-1}{\sqrt{\operatorname{Var}(S)}}, \text { if } S>0 \\
0 \ldots \ldots \ldots, \text { if } S=0 \\
\frac{S+1}{\sqrt{\operatorname{Var}(S)}}, \text { if } S<0
\end{array}\right.
$$

The statistical parameters are: $X_{i}$ and $X_{j}$ consecutive data values in the year $i$ and $j, n$ is the number of recorded data, $t p$ is the number of ties for the pth values, and $q$ is the number of tied values.

The rising trend values are identified with the positive $Z$ values, whereas the negative $Z$ values indicate a decreasing trend of the corresponding time series. The null hypothesis is represented as $\mathrm{H}_{0}$ and alternate hypothesis is denoted as $\mathrm{H}_{1}$ in the two-tailed test. If there is no trend in the series, $\mathrm{H}_{0}$ is rejected. If there is a trend in the series, $\mathrm{Z}$ value is acquired from the standard normal distribution with the pre-stated significance level.

\section{Sen's Slope Estimator}

The magnitude of the trend is quantified by a medianbased non-parametric slope estimator known as TheilSen method [17-18]. The computation of slope is given by Equation 3.5:

$$
\beta=\operatorname{median} \frac{x_{j}-x_{k}}{j-k} \ldots \ldots \forall \ldots k<j
$$

...where $x_{j}$ and $x_{k}$ are the consecutive data values of series in the years $\mathrm{j}$ and $\mathrm{k}$, and $\beta$ is the magnitude of the trend slope of data values.

\section{Change Point Detection Method}

The change point detection method is an effective tool to recognize the Climate erraticism in the historical climate data series. The recognition of change point location in the climate series is vital since it modifies processes in the hydrological cycle. A combination of cumulative sum charts (CUSUM) and boot strapping is a method used to detect changes by several iterations [19]. The cumulative sum $\mathrm{S}_{\mathrm{i}}$ is estimated by equation 3.6 as follows:

$$
S_{i}=S_{i-1}+X_{i}-\bar{X}
$$

...where $\mathrm{S}_{0}=0$; initial cumulative sum $\mathrm{S}_{0} ; \mathrm{i}=1,2$, $3, \ldots \ldots \ldots \ldots, 25$; and $\bar{X}$ is the average of the sample series.

The difference between current value and the average to the previous sum are added to compute the CUSUM values. The upward and downward slope indicates that the period of time where the values are above or below the overall average. At the change point, the series having two means are split into segments and through the iterative process mean square of estimates is computed till the minimum mean square of error (MSE) is reached. This shows the change of time and ultimately endorses the change in the climate system. The boot strapping-based confidence level is utilized to determine the significance of the change point as given in Equation 3.7:

$$
\text { Confidence level }=100 \times \frac{X}{N} \%
$$

...where $S_{\sim}$ is the difference between the maximum and minimum CUSUM values, $X$ is the number of bootstrapped $S_{\sim}$ values greater than the original $S_{\sim}$ values, and $\mathrm{N}$ is the number of bootstraps.

The change point analyzer is a Microsoft Excel-based add-on software utilized for change point detection in the dataset. This analyzer is an efficient tool that detects the exact year when the change or shift that has been taken place by using MSE and CUSUM charts. The level of change and confidence levels indicates the major change point in the entire dataset. The likelihood of climate shift from the observation year is shown by the steady rise or decline lines in the CUSUM plots, which are computed by equation 3.7. If there is no change present in the data series, then the values normally oscillate between the horizontal axis.

\section{Results and Discussion}

Based on the Mann-Kendall test and Change point analyzer, the trends and change points were identified for the rainfall and temperature data. Twenty-two rain gauge stations and one temperature station is involved in the present study as depicted in Fig. 2.

\section{Analyzing Monthly, Seasonal, and Annual Temperatures}

We utilized the past 38 years of data for trend analysis and change point detection studies. The monthly, seasonal, and annual means of maximum, minimum, and mean temperatures indicated that there is an increasing trend. For all cases, the trends are considered statistically significant when $\alpha$ value is equal to 0.05 . The maximum temperatures in March and September showed a significantly higher rising trend, with highest $Z$ values of 2.96 and 2.73, respectively. The minimum temperatures in May and June specified that significant higher rising trend with highest $Z$ values as 4.46 and 3.69, respectively. 


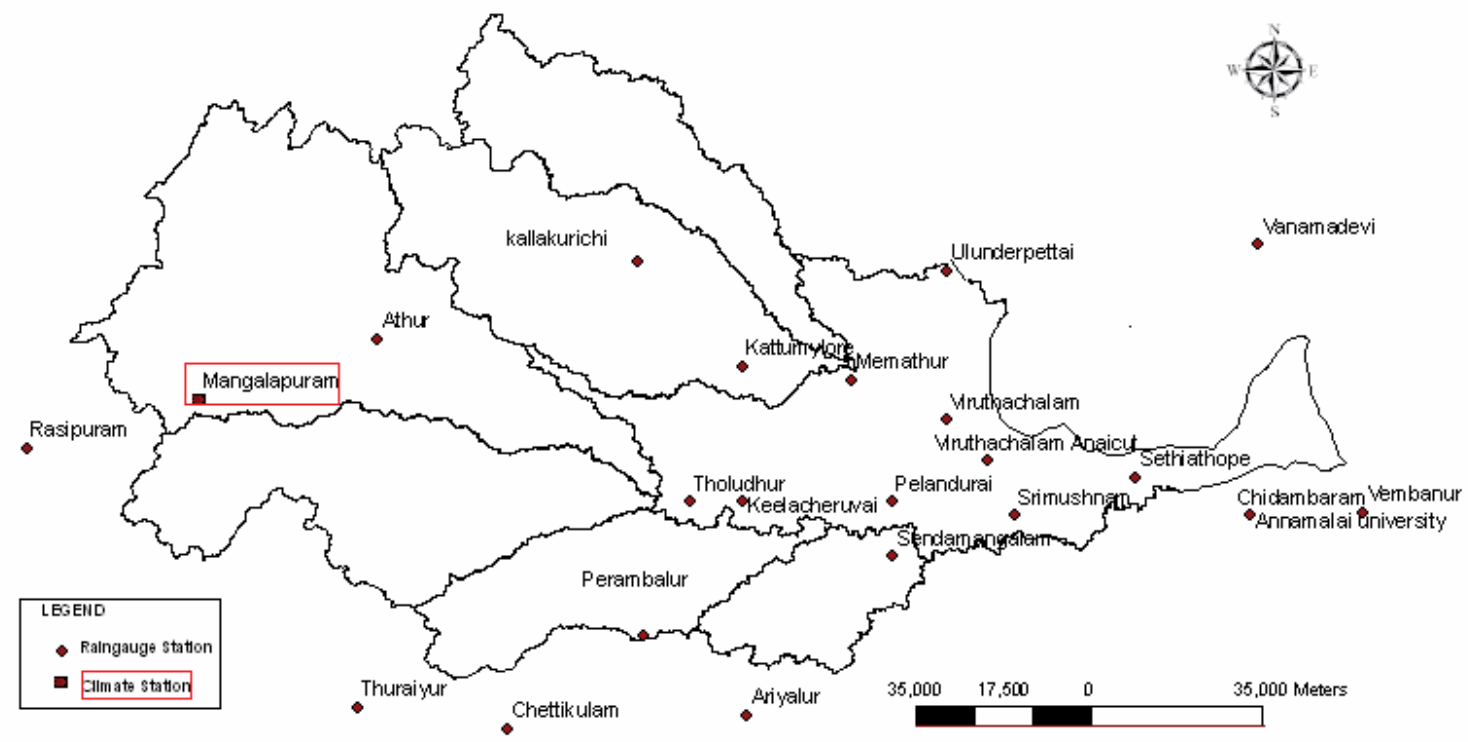

Fig. 2. Rain gauge and climate station of Vellar River Basin.

However, the minimum increasing trend is observed in the months of October and December for maximum temperature, and January and September for minimum temperature (Table 1). The mean temperature indicated that June and November see a significant rising trend with greater $\mathrm{Z}$ values as shown in Table 1 . All the monthly, seasonal, and annual maximum, minimum, and mean temperature results obtained from the Mann-Kendall test

Table 1. Mann-Kendall statistics for monthly, seasonal, and annual temperatures.

\begin{tabular}{|c|c|c|c|c|c|c|c|c|c|}
\hline Time Scale & \multicolumn{3}{|c|}{ Maximum Temperature } & \multicolumn{3}{|c|}{ Minimum Temperature } & \multicolumn{3}{|c|}{ Mean Temperature } \\
\hline Monthly Statistics & $\mathrm{Z}$ & Sen's slope & $\mathrm{P}$ & Z & $\begin{array}{l}\text { Sen's } \\
\text { slope }\end{array}$ & $\mathrm{P}$ & Z & $\begin{array}{l}\text { Sen's } \\
\text { slope }\end{array}$ & $\mathrm{P}$ \\
\hline January & 2.13 & 0.087 & 0.033 & 1.96 & 0.068 & 0.050 & 2.28 & 0.081 & 0.022 \\
\hline February & 2.69 & 0.093 & 0.007 & 3.00 & 0.081 & 0.028 & 2.59 & 0.076 & 0.010 \\
\hline March & 2.96 & 0.099 & 0.003 & 2.64 & 0.032 & 0.008 & 2.11 & 0.048 & 0.035 \\
\hline April & 2.59 & 0.059 & 0.010 & 3.52 & 0.025 & 0.005 & 2.00 & 0.025 & 0.046 \\
\hline May & 2.68 & 0.051 & 0.048 & 4.46 & 0.056 & $<0.0001$ & 2.43 & 0.028 & 0.014 \\
\hline June & 2.02 & 0.05 & 0.044 & 3.69 & 0.045 & $<0.0001$ & 3.35 & 0.06 & $<0.0001$ \\
\hline July & 2.07 & 0.061 & 0.037 & 2.96 & 0.03 & 0.003 & 2.27 & 0.044 & 0.023 \\
\hline August & 2.45 & 0.068 & 0.014 & 2.86 & 0.036 & 0.004 & 3.28 & 0.051 & $<0.0001$ \\
\hline September & 2.73 & 0.078 & 0.006 & 2.00 & 0.033 & 0.046 & 3.09 & 0.054 & 0.002 \\
\hline October & 1.48 & 0.053 & 0.011 & 2.18 & 0.037 & 0.029 & 2.95 & 0.057 & 0.003 \\
\hline November & 2.53 & 0.039 & 0.028 & 2.03 & 0.036 & 0.041 & 3.48 & 0.077 & $<0.0001$ \\
\hline December & 1.52 & 0.065 & 0.034 & 2.37 & 0.085 & 0.018 & 2.28 & 0.083 & 0.022 \\
\hline \multicolumn{10}{|c|}{ Seasonal statistics } \\
\hline Winter & 2.27 & 0.085 & 0.022 & 2.57 & 0.067 & 0.009 & 2.69 & 0.092 & 0.007 \\
\hline Summer & 1.68 & 0.048 & 0.047 & 4.96 & 0.068 & $<0.0001$ & 2.36 & 0.023 & 0.018 \\
\hline Swm & 2.86 & 0.087 & 0.004 & 3.07 & 0.04 & 0.002 & 2.96 & 0.043 & 0.003 \\
\hline Nem & 2.35 & 0.052 & 0.016 & 2.03 & 0.046 & 0.041 & 1.75 & 0.029 & 0.081 \\
\hline Annual Statistics & 2.23 & 0.037 & 0.025 & 3.10 & 0.043 & 0.002 & 2.11 & 0.04 & 0.035 \\
\hline
\end{tabular}


Table 2. Mann-Kendall statistics for annual maximum daily, seasonal, and annual rainfall.

\begin{tabular}{|c|c|c|c|c|c|c|c|c|c|c|c|c|}
\hline \multirow{3}{*}{ Stations } & \multirow{2}{*}{\multicolumn{2}{|c|}{ Amdr Statistics }} & \multicolumn{8}{|c|}{ Seasonal Statistics } & \multirow{2}{*}{\multicolumn{2}{|c|}{ Annual Statistics }} \\
\hline & & & \multicolumn{2}{|c|}{ SWM } & \multicolumn{2}{|c|}{ NEM } & \multicolumn{2}{|c|}{ Winter } & \multicolumn{2}{|c|}{ Summer } & & \\
\hline & S & Z & S & Z & S & Z & S & Z & S & Z & S & Z \\
\hline Ariyalur & 1.00 & 1.12 & -5.491 & -2.06 & 6.175 & 2.03 & 0.00 & -0.13 & -0.755 & -0.26 & -0.217 & 1.12 \\
\hline Athur & 0.794 & 1.61 & 1.672 & 1.25 & 6.133 & 2.42 & 0.00 & -1.03 & 1.311 & 1.28 & 9.066 & 1.61 \\
\hline Chettikulam & 0.25 & 0.50 & -2.221 & -0.32 & 1.682 & 0.79 & 0.00 & -0.72 & 0.067 & 0.23 & -0.877 & 0.50 \\
\hline Chidambaram & 0.726 & 0.62 & -2.625 & -1.62 & 8.245 & 1.88 & 0.00 & 0.44 & 0.11 & 0.39 & 6.39 & 0.62 \\
\hline Kallakurichi & -3.132 & -0.92 & -10.82 & -4.29 & -10.46 & -3.58 & 0.00 & -2.60 & -1.729 & -2.88 & -23.17 & -0.92 \\
\hline Kattumylore & 1.192 & 1.45 & -6.182 & -2.45 & 9.639 & 3.39 & 0.00 & -1.00 & -0.99 & -0.29 & 3.98 & 1.45 \\
\hline Keelacheruvai & 2.393 & 2.40 & 2.961 & 1.31 & 13.57 & 3.10 & -0.109 & -1.24 & 1.674 & 1.74 & 18.836 & 2.40 \\
\hline Memathur & 2.129 & 3.05 & -12.46 & -3.16 & 4.943 & 1.99 & -0.024 & -1.24 & -0.987 & -0.45 & -8.84 & 3.05 \\
\hline Parangipettai & 0.684 & 0.96 & -1.618 & -0.28 & 10.15 & 2.25 & 0.041 & 0.57 & 2.078 & 1.83 & 11.85 & 0.96 \\
\hline Pelandurai & 0.854 & 1.07 & -0.346 & 0.31 & 13.36 & 3.65 & 0.00 & 0.74 & 2.613 & 1.87 & 14.284 & 1.07 \\
\hline Perambalur & 0.836 & 1.78 & 2.01 & 1.31 & 8.133 & 2.16 & 0.00 & -0.24 & 2.748 & 2.42 & 16.299 & 1.78 \\
\hline Rasipuram & -0.365 & -0.36 & 6.04 & -2.42 & 1.443 & 0.79 & 0.00 & -1.88 & -0.351 & 0.11 & -6.418 & -0.36 \\
\hline Sendamangalam & -1.129 & -1.93 & -4.50 & -1.69 & 1.661 & 0.60 & 0.00 & -0.26 & -0.972 & -0.24 & -1.944 & -1.93 \\
\hline Sethiothope & 2.218 & 2.34 & -0.764 & 0.05 & 14.68 & 3.00 & 0.074 & 0.56 & 1.438 & 1.65 & 13.814 & 2.34 \\
\hline Sethiothope Anicut & 2.342 & 2.66 & -3.616 & -1.59 & 9.832 & 2.19 & 0.00 & 0.43 & 1.683 & 1.46 & 4.967 & 2.66 \\
\hline Srimushnam & 2.776 & 2.87 & -2.502 & -0.54 & 8.976 & 2.16 & 0.00 & 0.10 & -0.081 & 0.28 & 3.519 & 2.87 \\
\hline Tholudur & 2.867 & 2.39 & 4.121 & 1.77 & 16.42 & 4.52 & 0.00 & -0.25 & 3.063 & 2.21 & 29.00 & 2.39 \\
\hline Thuraiyur & -0.271 & -0.45 & -1.587 & -0.31 & 1.092 & 0.79 & 0.00 & 0.03 & 2.829 & 1.64 & 3.046 & -0.45 \\
\hline Ulundurpet & 1.913 & 2.64 & -4.323 & -1.25 & 10.13 & 3.32 & 0.00 & 0.00 & 1.227 & 1.41 & 7.145 & 2.64 \\
\hline Vembanur & 0.643 & 0.49 & 0.00 & 0.45 & 0.00 & 0.63 & 0.00 & -0.26 & 2.206 & 1.95 & 1.189 & 0.49 \\
\hline Virudhachalam & 1.512 & 1.35 & -1.764 & -0.32 & 12.60 & 3.36 & 0.00 & 0.05 & 2.088 & 1.01 & 13.092 & 1.35 \\
\hline Virudhachalam Anicut & 0.429 & 0.58 & -10.46 & -3.09 & -8.445 & -1.34 & 0.00 & -1.75 & -2.057 & -2.21 & -24.07 & 0.58 \\
\hline
\end{tabular}

revealed that a significant greater rising trend is present in the series. The magnitude of Sen's slope of all the monthly, seasonal, and annual maximum, minimum, and mean temperatures specifies that there is a significant rising trend in the study area. The maximum temperature represented the greatest values of $41.6^{\circ} \mathrm{C}, 40.4^{\circ} \mathrm{C}$, and $38.9^{\circ} \mathrm{C}$ in 2002 during April, March, and summer, respectively. The greatest values of $26.9^{\circ} \mathrm{C}, 25.7^{\circ} \mathrm{C}$, and $25.1^{\circ} \mathrm{C}$ in 2003 during May, April, and June is identified for minimum temperature. The magnitude of annual mean maximum temperature shows an increasing trend of $0.2^{\circ} \mathrm{C}$ and $0.6^{\circ} \mathrm{C}$ per decade.

A warming trend is observed from both maximum and minimum temperature characteristics. A significant rising trend of mean annual temperature shows that there is an alarming global warming signal expressed over the entire river basin. An increase of $0.5^{\circ} \mathrm{C}$ in the annual mean temperature is noted in the recent decade within the study period of 38 years. Thus the results indicate that there is a consistent warming trend during the previous three decades. The greatest monthly temperatures of $41.6^{\circ} \mathrm{C}$ and $40.4^{\circ} \mathrm{C}$ are noticed in April and March, and the lowest monthly temperatures of $17^{\circ} \mathrm{C}$ and $18^{\circ} \mathrm{C}$ are observed in January and December.

\section{Analying Annual Maximum, Seasonal, and Annual Precipitation}

The Mann-Kendall trend test is carried out for the rainfall series of the 22 rain gauge stations located in the river basin. The estimated Mann-Kendall $\mathrm{Z}$ and $p$ values of each station for annual maximum, seasonal, and annual time scales are shown in Tables 2-3. The seasonal rainfall time series are more substantial than annual time series because they are subjected to greater inter-annual variability. The trend results were abbreviated as IT (increasing trend), DT (decreasing trend), and NT (no trend) in Table 3. A statistically significant increasing trend is seen in the AMDR statistics of six stations: Keelacheruvai, Memathur, Sethiothope, Sethiothope 
Table 3. Trend analysis of annual maximum daily, seasonal, and annual rainfall.

\begin{tabular}{|c|c|c|c|c|c|c|c|c|c|c|c|c|}
\hline \multirow{3}{*}{ Stations } & \multirow{2}{*}{\multicolumn{2}{|c|}{ Amdr Statistics }} & \multicolumn{8}{|c|}{ Seasonal Statistics } & \multirow{2}{*}{\multicolumn{2}{|c|}{$\begin{array}{l}\text { Annual } \\
\text { Statistics }\end{array}$}} \\
\hline & & & \multicolumn{2}{|c|}{ SWM } & \multicolumn{2}{|c|}{ NEM } & \multicolumn{2}{|c|}{ Winter } & \multicolumn{2}{|c|}{ Summer } & & \\
\hline & $\mathrm{P}$ & Trend & $\mathrm{P}$ & Trend & $\mathrm{P}$ & Trend & $\mathrm{P}$ & Trend & $\mathrm{P}$ & Trend & $\mathrm{P}$ & Trend \\
\hline Ariyalur & 0.263 & NT & 0.024 & DT & 0.111 & NT & 0.644 & NT & 0.535 & NT & 0.988 & NT \\
\hline Athur & 0.108 & NT & 0.433 & NT & 0.019 & IT & 0.196 & NT & 0.433 & NT & 0.045 & IT \\
\hline Chettikulam & 0.614 & NT & 0.438 & NT & 0.701 & NT & 0.342 & NT & 0.951 & NT & 0.842 & NT \\
\hline Chidambaram & 0.538 & NT & 0.063 & NT & 0.173 & NT & 0.815 & NT & 0.926 & NT & 0.317 & NT \\
\hline Kallakurichi & $<0.0001$ & DT & 0.0001 & DT & 0.001 & DT & 0.006 & NT & 0.002 & DT & $<0.0001$ & DT \\
\hline Kattumylore & 0.148 & NT & 0.0009 & DT & 0.002 & IT & 0.209 & NT & 0.457 & NT & 0.415 & NT \\
\hline Keelacheruvai & 0.016 & IT & 0.274 & NT & 0.003 & IT & 0.132 & NT & 0.239 & NT & 0.009 & IT \\
\hline Memathur & 0.002 & IT & 0.001 & DT & 0.092 & NT & 0.133 & NT & 0.403 & NT & 0.223 & NT \\
\hline Parangipettai & 0.338 & NT & 0.570 & NT & 0.065 & NT & 0.651 & NT & 0.092 & NT & 0.190 & NT \\
\hline Pelandurai & 0.284 & NT & 0.939 & NT & 0.001 & IT & 0.729 & NT & 0.085 & NT & 0.002 & IT \\
\hline Perambalur & 0.074 & NT & 0.348 & NT & 0.065 & NT & 0.749 & NT & 0.024 & IT & 0.005 & IT \\
\hline Rasipuram & 0.721 & NT & 0.007 & DT & 0.634 & NT & 0.038 & NT & 0.724 & NT & 0.223 & NT \\
\hline Sendamangalam & 0.050 & DT & 0.059 & NT & 0.509 & NT & 0.634 & NT & 0.466 & NT & 0.770 & NT \\
\hline Sethiothope & 0.019 & IT & 0.747 & NT & 0.011 & IT & 0.639 & NT & 0.204 & NT & 0.065 & NT \\
\hline Sethiothope Anicut & 0.008 & IT & 0.051 & NT & 0.075 & NT & 0.923 & NT & 0.239 & NT & 0.415 & NT \\
\hline Srimushnam & 0.004 & IT & 0.348 & NT & 0.086 & NT & 0.923 & NT & 0.877 & NT & 0.701 & NT \\
\hline Tholudur & 0.017 & IT & 0.179 & NT & $<0.0001$ & IT & 0.575 & NT & 0.107 & NT & 0.0001 & IT \\
\hline Thuraiyur & 0.650 & NT & 0.451 & NT & 0.678 & NT & 0.924 & NT & 0.086 & NT & 0.364 & NT \\
\hline Ulundurpet & 0.008 & IT & 0.104 & NT & 0.003 & IT & 0.759 & NT & 0.386 & NT & 0.179 & NT \\
\hline Vembanur & 0.626 & NT & 0.582 & NT & 0.507 & NT & 0.634 & NT & 0.029 & IT & 0.521 & NT \\
\hline Virudhachalam & 0.180 & NT & 0.476 & NT & 0.003 & IT & 0.799 & NT & 0.227 & NT & 0.08 & NT \\
\hline Virudhachalam Anicut & 0.559 & NT & 0.002 & DT & 0.17 & NT & 0.059 & NT & 0.014 & DT & 0.013 & DT \\
\hline
\end{tabular}

anaicut, Srimushnam, and Tholudur and Ulundurpet. Seasonal trend statistics indicated an increasing trend observed for Perambalur and Vembanur stations and a decreasing trend in Kallakurichi and Virudhachalam anaicut stations in summer. A statistically insignificant trend is perceived in all the stations for winter, and a decreasing trend was observed in six stations, and the other stations are having a statistically insignificant trend for the SWM season shown in Table 3. For the NEM season, a statistically significant increasing trend is specified in eight stations except Kallakurichi, which shows a decreasing trend and other stations are having an insignificant trend as depicted in Table 3. A statistically significant increasing trend resulted in five stations except Kallakurichi and Vridhachalam Anaicut stations, which shows a decreasing trend, and other stations are having an insignificant trend as depicted in Table 3.

The Sen's slope is utilized to compute trend magnitude. In AMDR statistics, the greatest increase in trend magnitude is seen in Memathur station by $3.05 \mathrm{~mm} / 10$ years. Sendamangalam station has a decreasing rainfall trend magnitude of $1.9 \mathrm{~mm} / 10$ years. The magnitude of increasing trends in NEM and SWM are greater than that of summer and winter seasons for almost all the stations. The 2005 year is the surplus year in the period of study, with rainfall of $1,470 \mathrm{~mm}$, which is above the average rainfall.

\section{Analysis of Change Points}

The recognition of change points is a statistical technique that plays a vital role in spotting climate jumps in the whole climatological data period. The change points were identified for maximum, minimum, and mean temperatures. It is clearly evident that the maximum, minimum, and mean temperature values appear to be outside the control limits, which reveals that change took place during the examined data period (Fig. 3).

The level represented in Fig. 4 implies change and is strongly linked with climate change. The maximum 

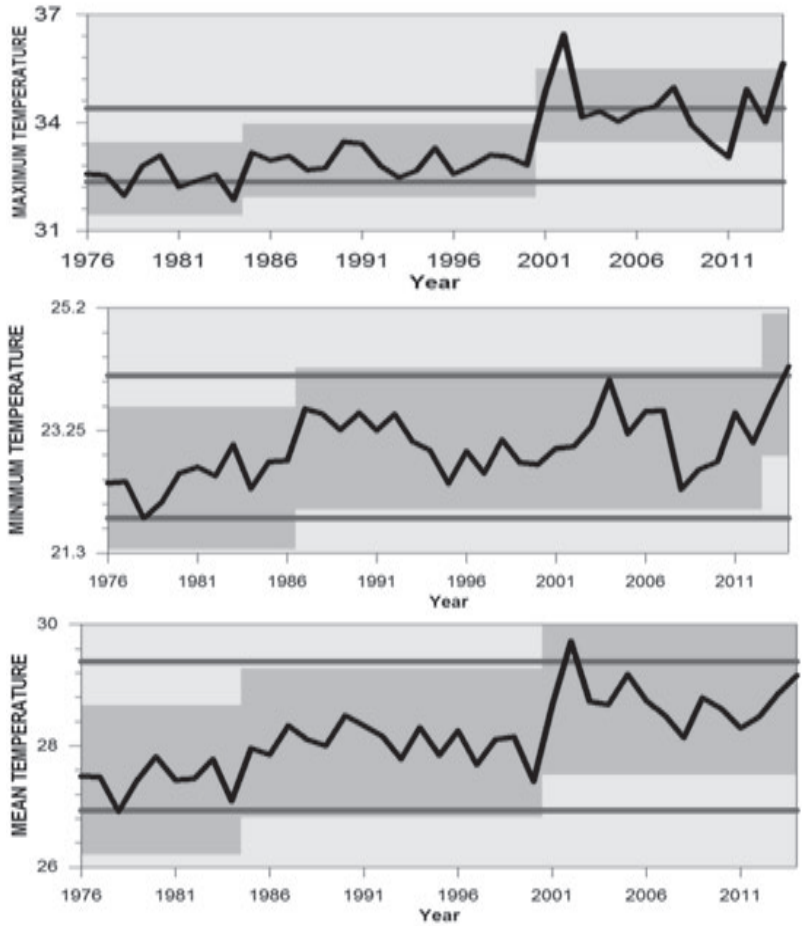

Fig. 3. Identifying change points for annual temperature.

temperature change point occurred in 1985 and 2001 at a confidence level of $100 \%$ and $94 \%$ at levels 2 and 1 , respectively. Before the existence of the change the mean maximum temperature was $32.94^{\circ} \mathrm{C}$ during 1985 , and after the change the value was $34.46^{\circ} \mathrm{C}$. In the case of minimum temperature, the change point appeared in 1987 and 2013 at $100 \%$ and $91 \%$ confidence interval at levels 1 and 3, respectively. Earlier to the change, the minimum temperature is $23.11^{\circ} \mathrm{C}$ and after the change, it had a value of $23.97^{\circ} \mathrm{C}$. From the mean annual temperature, it is seen that the change point is present in 1983-1988 and
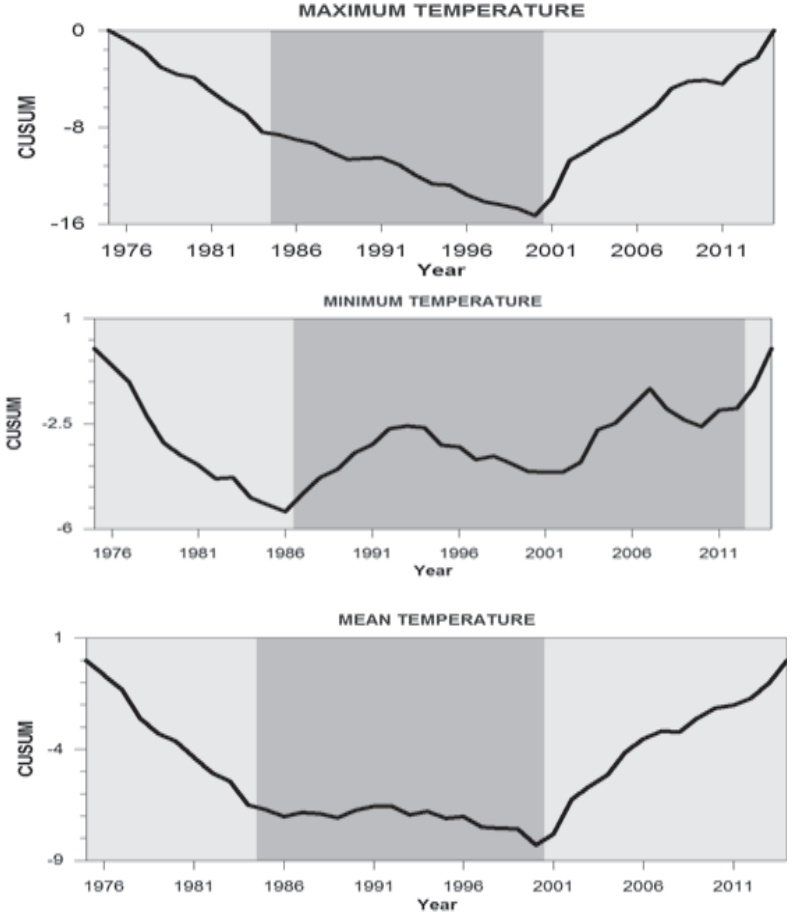

Fig. 5. CUSUM chart for annual temperature.

2000-2004 at 100\% confidence interval at levels 4 and 3, respectively. The change point years are clearly shown in Fig. 4. The change point magnitude is computed using the ratio of average of climate data after the change point to the before the change point occurrence is found to be 0.99 , 1.00 , and 1.00 , correspondingly.

The present study shows a statistical importance of change point that can be seen from the late 1980s at a confidence interval setting of $95 \%$ with 1,000 boot straps and a method of mean square of estimates. The process shifts estimation and generation of trends are well

\begin{tabular}{|c|c|c|c|c|c|}
\hline Year & Confidence Interval & Conf. Level & From & To & Level \\
\hline 1985 & $(1980,1989)$ & $94 \%$ & 32.438 & 32.943 & 2 \\
\hline 2001 & $(2001,2004)$ & $100 \%$ & 32.943 & 34.465 & 1 \\
\hline Year & Confidence Interval & Conf. Level & From & To & Level \\
\hline 1987 & $(1985,1993)$ & $100 \%$ & 22.494 & 23.119 & 1 \\
\hline 2013 & $(1997,2013)$ & $91 \%$ & 23.119 & 23.978 & 3 \\
\hline Year & Confidence Interval & Conf. Level & From & To & Level \\
\hline 1985 & $(1983,1988)$ & $100 \%$ & 27.437 & 28.048 & 4 \\
\hline 2001 & $(2000,2004)$ & $100 \%$ & 28.048 & 28.754 & 3 \\
\hline
\end{tabular}

Fig. 4. Estimated change point years for annual temperature. 


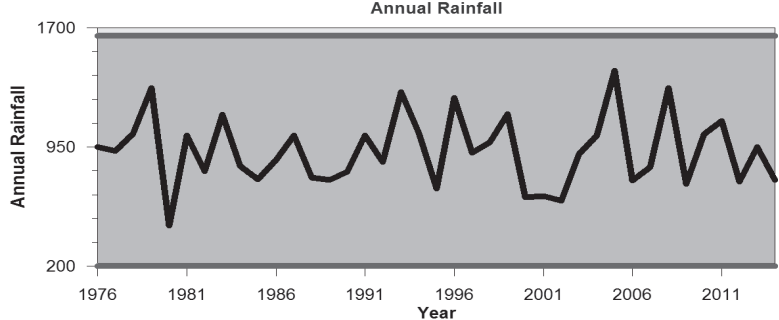

Fig. 6. Estimated change point years for annual rainfall.

indicated using CUSUM charts. The CUSUM chart of maximum, minimum, and mean temperatures obtained by the boot-strapping technique has a noticeable change at $\alpha=0.05$, which is depicted by modified background color in Fig. 5. A clear upward trend is represented in CUSUM charts and a sudden temperature change is found in the late 1980s and 2000s. The increasing trend continues until 2014. The estimated change point years of annual rainfall is shown in Fig. 6. The results of annual rainfall change point years shows no major change, which is due to the characteristic of highly erratic and inter annual variability.

\section{Conclusions}

The variability of rainfall and temperature due to probable human involvement or change in climate is essential for planning and managing water resources at a regional level. Different non-parametric tests were used for trend analysis and change point detection. The results show that all monthly, seasonal, and annual maximum, minimum, and mean temperatures have a significant greater rising trend. The magnitude of increasing trends in NEM and SWM are greater than those of summer and winter seasons for almost all the rain gauge stations. The previous studies also validated that the river basin in the Northern part of Tamil Nadu is experiencing an increase in temperature and rainfall, and a decrease in rainy days. The maximum temperature and minimum temperature change points are identified in 1985 and 2001, and 1987 and 2013 , respectively. From the mean annual temperature, it is seen that the change point is present in 1983-88 and 2000-04 at 100\% confidence interval. The important change points observed in maximum, minimum, and mean temperatures implies that there is an influence of fast-growing industrial activities in the basin and also the increase in temperature occurred by change in land use pattern, which is caused by the effect of excessive stream flow during monsoon season and thereafter a long dry period prevailed in the basin. The present study is very helpful in framing climate change scenarios and it is based on the revealed characteristics of climate variables at the regional level.

\section{Acknowledgements}

The authors acknowledge sincere thanks for data support from the Vellar River Basin Project, Centre for Water resources, Anna University.

\section{References}

1. HARTMANN D.L., TANK A.M.K., RUSTICUCCI M., ALEXANDER L.V., BRONNIMANN S., CHARABI Y.A.R., DENTENER F.J., DLUGOKENCKY E.J., EASTERLING D.R., KAPLAN A., SODEN B.J., THORNE P.W., WILD M., ZHAI P.M. Observations: atmosphere and surface. In: Climate Change 2013: The Physical Science Basis. Working Group I Contribution to the Fifth Assessment Report of the Intergovernmental Panel on Climate Change, Cambridge University Press, Cambridge, United Kingdom and New York, 159, 2013.

2. JAIN S.K., KUMAR V. Trend analysis of rainfall and temperature data for India. Current Science. 102 (1), 37, 2012.

3. GAO P., DENG J., CHAI X., MU X., ZHOU G., SHAO H., SUN W. Dynamic sediment discharge in the Hekou-Longman region of Yellow river and soil and water conservation implications. Science of The Total Environment. 578, 56, 2017.

4. NOURI M., HOMAEE M., BANNAYAN M. Quantitative trend, sensitivity and contribution analyses of reference evapotranspiration in some arid environments under climate change. Water Resources Management. 31 (7), 2207, 2017.

5. OZGUR K.I.S.I., OKAN E.R.A.Y., CIHAN M.E.R.T. Trend analysis of long term temperatures in Tbilisi, Georgia. Journal of Technical Science \& Technologies. 5 (2), 59, 2017.

6. ZARENISTANAK M., DHORDE A.G., KRIPALANI R.H. Trend analysis and Change point detection of annual and seasonal precipitation and temperature series over southwest Iran. Journal of earth system science. 123 (2), 281, 2014.

7. JAISWAL R.K., LOHANI A.K., TIWARI H.L. Statistical analysis for change detection and trend assessment in climatological parameters. Environmental Processes. 2 (4), 729, 2015.

8. SIVAKUMAR A.T., THENNARASU A., RAJKUMAR J.S.I. Effect of season on the incidence of infectious diseases of bovine in Tamilnadu. Elixir Meteorology. 47, 8874, 2012.

9. SHARMA S., SWAYNE D.A., OBIMBO C. Trend analysis and change point techniques: a survey. Energy, Ecology and Environment, 1 (3), 123, 2016.

10. HUANG H., WANG Z., XIA F., SHANG X., LIU Y., ZHANG M., DAHLGREN R.A., MEI K. Water quality trend and change-point analyses using integration of locally weighted polynomial regression and segmented regression. Environmental Science and Pollution Research. 24, 1, 2017.

11. BATISANI N., YARNAL B. Rainfall variability and trends in semi-arid Botswana: implications for climate change adaptation policy. Applied Geography. 30 (4), 483, 2010.

12. KARPOUZOS D.K., KAVALIERATOU S., BABAJIMOPOULOS C. Trend analysis of precipitation data in Pieria region (Greece). European Water. 30, 31, 2010. 
13. OBASI R.A., IKUBUWAJE C.O. Analytical study of rainfall and temperature trend in catchment states and stations of the Benin-Owena river basin, Nigeria. Journal of Environment and Earth Science. 2 (3), 9, 2012.

14. SALARIJAZI M., AKHOND-ALI A.M., ADIB A., DANESHKHAH A. Trend and change point detection for the annual stream-flow series of the Karun River at the Ahvaz hydrometric station. African Journal of Agricultural Research. 7 (32), 4540, 2012.

15. KENDALL M.G. Rank correlation methods, Charles Griffin, London, 1975.

16. MANN H.B. Non parametric tests against trend. Econometrica: Journal of the econometric society. 13 (3), 245, 1945.
17. SEN P.K. Estimates of the regression coefficient based on Kendall's tau. Journal of the American Statistical Association. 63 (324), 1379, 1968

18. THEIL H. A rank-invariant method of linear and polynomial regression analysis, Part I, II, III, In Proceedings of Koninalijke Nederlandse Akademie van Weinenschatpen A. 53, 386, 512, 1397, 1950.

19. TAYLOR W.A. Change-Point Analyzer 2.3 software package, Taylor Enterprises, Libertyville, Illinois, 2000, online may be assessed at http://www.variation.com/cpa/tech/ change point (3 January 2017). 
